\title{
Effects of acetazolamide and temazepam on sleep at high altitude (Abstract)
}

\author{
A.N. Nicholson, P.A. Smith, B.M. Stone, A.R. Bradwell and J.H. Coote \\ Royal Air Force Institute of Aviation Medicine, Farnborough, Hants and University of Birmingham, Birmingham, \\ UK.
}

During an expedition to the Himalayas the sleep of six trekkers was recorded electroencephalographically between 1000 and $1800 \mathrm{~m}, 2700$ and $3600 \mathrm{~m}$ and 4100 and $4846 \mathrm{~m}$. Three of the subjects ingested acetazolamide $500 \mathrm{mg} /$ day during the ascent and the other three ingested placebo.

There was some evidence that the subjects adapted to the relatively uncomfortable sleeping conditions during the initial part of the ascent. However at 4100 to $4846 \mathrm{~m}$, compared with 2700 to $3600 \mathrm{~m}$, there was difficulty in falling asleep, (mean sleep onset latencies 11.9 and 38.8 minutes respectively), marked reduction in sleep duration in the first 6 hours of the night (314.5 and 263.8 minutes respectively) and reduced sleep efficiency index ( 0.87 and 0.70 respectively). When the sleep of the subjects who ingested acetazolamide was compared with the sleep of placebo subjects over the three altitudes, wakefulness and drowsy sleep were reduced (91.7 and 56.6 minutes respectively), sleep duration in the first 6 hours was increased (230.6 and 309.0 minutes respectively) and sleep efficiency was improved ( 0.75 and 0.83 respectively). All comparisons were significant at the $5 \%$ level.

Temazepam was also used between 4100 and $4846 \mathrm{~m}$ and led to less wakefulness and drowsy sleep (136.1 and 53.8 minutes respectively) and increased sleep duration in the first 6 hours (230.9 and 290.0 minutes respectively). There were no prolonged sleep latencies in subjects who used temazepam, and in subjects who used both acetazolamide and temazepam sleep efficiency was at sea level values. There was improved sleep with acetazolamide and difficulties in falling asleep were avoided with temazepam, while acetazolamide and temazepam together appeared to sustain sleep. These studies would suggest that both acetazolamide and temazepam have a useful role in the management of altitude insomnia.

\section{Effects of almitrine and acetazolamide on ventilation (Abstract)}

\author{
G.L. Harrison, P.H. Hackett, R.C. Roach, R.B. Schoene and W.J. Mills \\ Division of Respiratory Disease, Harborvier Medical Centre, Seattle, Washington, USA.
}

Periodic breathing and hypoxaemia occur frequently during sleep at high altitude and are diminished by acetazolamide. Almitrine is a ventilatory stimulant which may prevent sleep disturbance at high altitude. In a double blind and randomized fashion the effect of almitrine, acetazolamide and placebo on the control of ventilation and sleep was studied in five healthy climbers in a heated laboratory on Mount McKinley $(4400 \mathrm{~m})$. Poikilocapnic hypoxic ventilatory response (HVR) and the ventilatory response to oxygen breath- ing was measured during the waking state. Arterial oxygen saturation and pattern of breathing were measured during 3 hour sleep studies. HVR ( - VE/ $\left.-\mathrm{SaO}_{2}\right)$ was augmented with almitrine $(-0.9 \pm 1.0)$ compared with placebo and acetazolamide (both $-0.6 \pm 0.5$ ). Oxygen breathing decreased ventilation more with almitrine $(-19.0 \pm 27.0 \%)$ and placebo $(-21.1 \pm 18.0 \%)$ than with acetazolamide $(-2.5 \pm 10.0 \%)$ $(P<0.05)$. Almitrine and acetazolamide both increased arterial oxygen saturation during sleep although

C The Fellowship of Postgraduate Medicine, 1987 